\title{
Distribution of sperm counts in suspected infertile men
}

\author{
D. Mortimer and Elizabeth A. Lenton*
}

Department of Obstetrics \& Gynaecology, University of Birmingham, Birmingham B15 2TG, U.K. and $^{*}$ Department of Obstetrics \& Gynaecology, University of Sheffield, Jessop Hospital for Women, Sheffield S3 7RE, U.K.

\begin{abstract}
Summary. Probit plots of sperm concentration for 1711 suspected infertile men (those with azoospermia being excluded) were compared for the untransformed and $\log _{e} e^{-}$, square root- and cube root-transformed values. For the distribution of sperm concentrations, which was highly skewed towards low values, the square-root transformation produced the most normal (Gaussian) distribution. $\log _{e}$ and cube-root transformations caused skewing towards high values. Such treatment of the data should always be considered before using parametric statistical tests to make comparisons between sperm concentrations of groups of men.
\end{abstract}

\section{Introduction}

Several studies have reported the distribution of sperm concentration to be skewed towards low values, the degree of skewness varying not only between populations of fertile and suspected infertile men, but also between different study populations due to either recruitment methods or referral practices (Nelson \& Bunge, 1974; Rehan, Sobrero \& Fertig, 1975; Sobrero \& Rehan, 1975; Zukerman, Rodriguez-Rigau, Smith \& Steinberger, 1977; Bahamondes, Abdelmassin \& Dachs, 1979; David, Jouannet, Martin-Boyce, Spira \& Schwartz, 1979; MacLeod \& Wang, 1979; Homonnai, Paz, Weiss \& David, 1980; Heuchel, Schwartz \& Price, 1981 ; Jouannet et al., 1981; Mortimer, Templeton, Lenton \& Coleman, 1982a). Table 1 summarizes the available quantitative information on the means and ranges of sperm concentration from the larger published studies. Whenever a $95 \%$ range could be calculated (as mean $\pm 1.96 \mathrm{s.d}$.), the lower limit of the range was negative, which is clearly impossible. Furthermore, the upper $95 \%$ range limit was always appreciably less than the quoted highest values. These basic findings cause complications when comparisons between mean values are attempted by using parametric statistical tests (e.g. James, 1980). A mean value from a strongly-skewed distribution says very little about that population, and simple computation of its variance (and hence standard deviation or standard error of the mean) is not very useful. Application of $t$ tests, which assume normal (Gaussian) distribution of the data, is often invalid. Indeed, a common problem remarked upon by andrologists has been that the mean sperm concentrations for groups of men of different clinical status were of little or no use for discrimination of the groups. With the increasing awareness of the adverse effects of various environmental pollutants and certain pharmacological products upon sperm production (Eliasson, 1978; Wyrobek \& Bruce, 1978; Toth, 1979; Drife, 1982), some rational approach to making such comparisons is clearly required. Several authors have used data transformations to normalize sperm concentration distributions, e.g. logarithms (Rehan et al., 1975; Sobrero \& Rehan, 1975; Bahamondes et al., 1979; Heuchel et al., 1981 ; Mortimer et al., 1982a, c), square roots (MacLeod \& Wang, 1979) and cube roots (Bahamondes et al., 1979). 


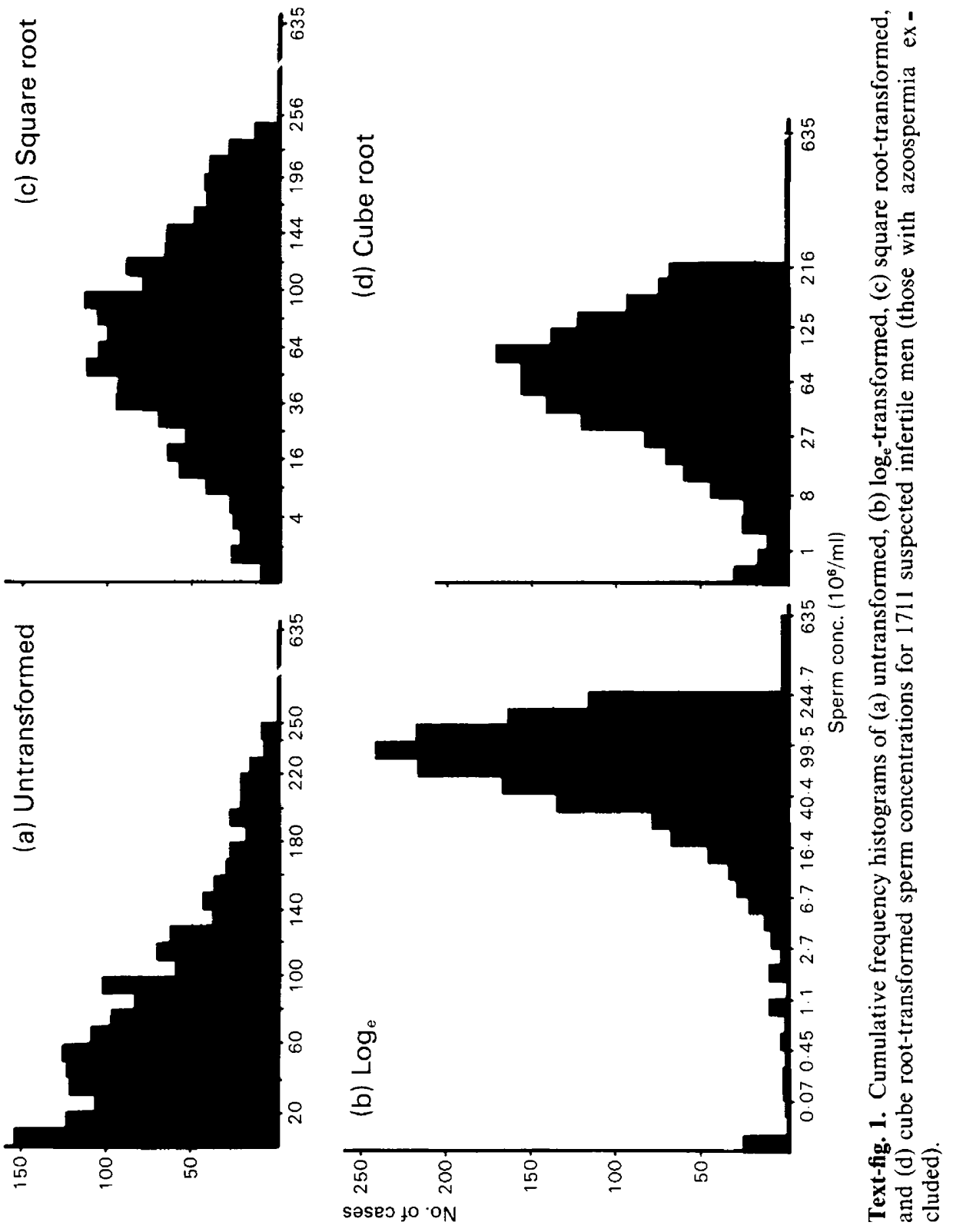



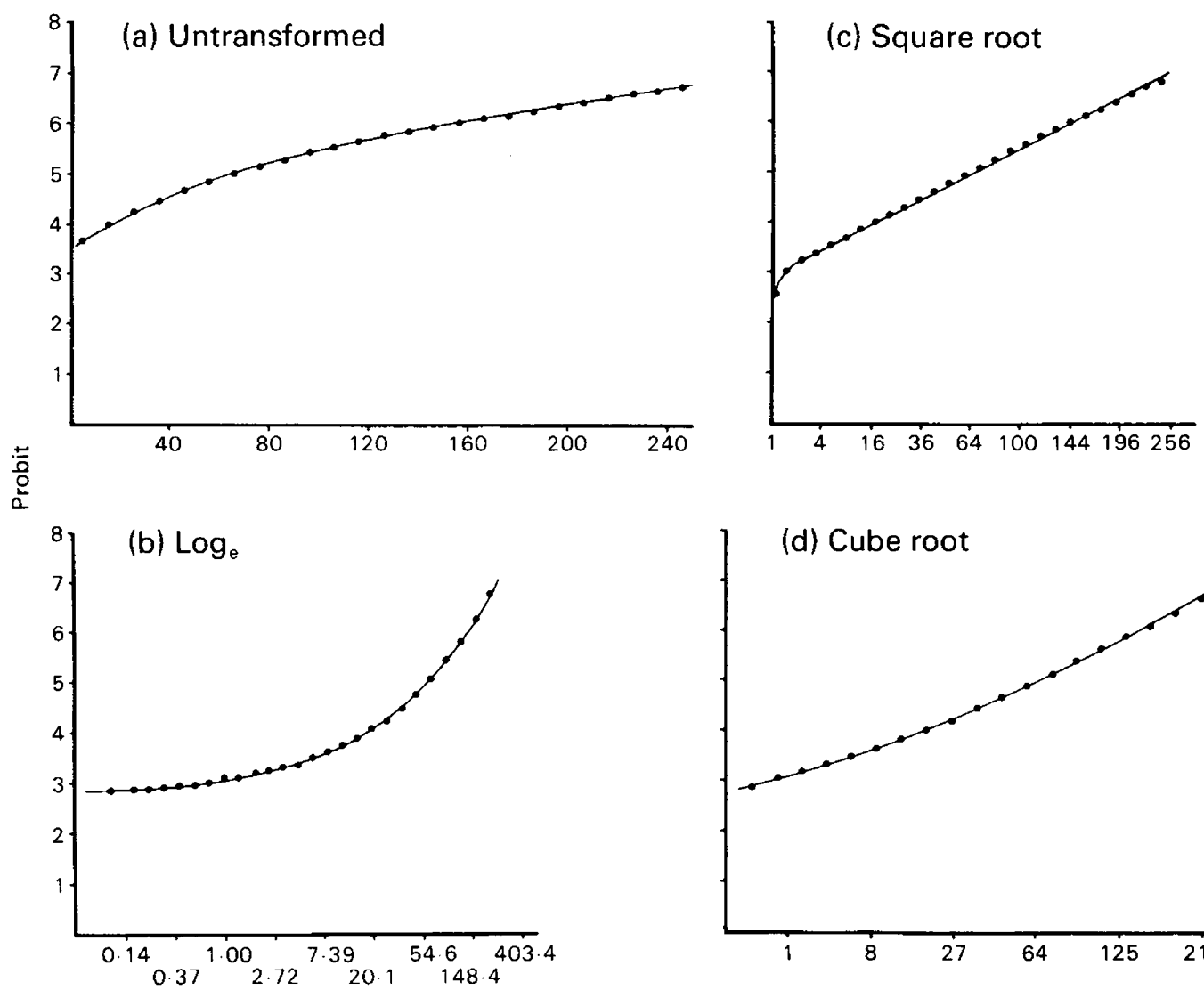

(d) Cube root

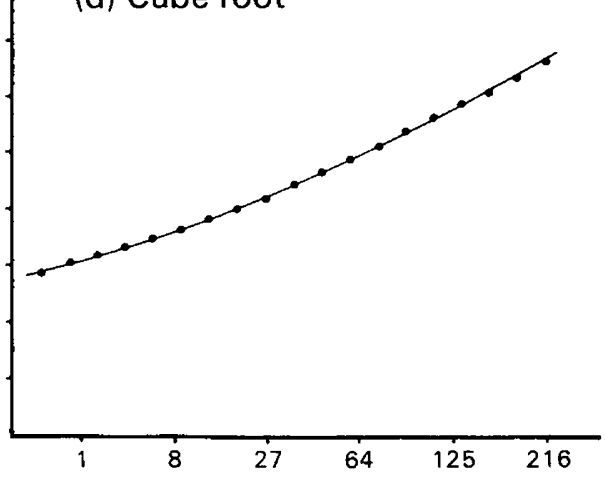

Sperm conc. $\left(10^{6} / \mathrm{ml}\right)$

Text-fig. 2. Probit plots of the cumulative frequencies for (a) untransformed, (b) $\log _{e}$ transformed, (c) square root-transformed and (d) cube root-transformed sperm concentrations for 1711 suspected infertile men (those with azoospermia excluded).

We have reported a statistical analysis of the semen characteristics of a population of suspected infertile men (Mortimer et al., 1982a, b, c) and have since been interested in determining the best normalizing transformation of sperm concentration data, thus enabling sensible use of means and variances. This paper reports the results of these computations.

\section{Materials and Methods}

The study material was the first semen analysis performed on the husband of each couple referred to the Infertility Service of the Edinburgh Royal Infirmary during the period 1 January 1975 to 31 May 1980 (Mortimer et al., 1982a, b). While no thorough clinical subdivision of the entire study sample has been possible, a sub-sample has been the subject of such an analysis (Templeton \& Penney, 1982). Cases of azoospermia were excluded to improve the correspondence of the sample to the population of fertile men in which this condition would not occur. These data were subjected to $\log _{e}$, square root and cube root transformations and, following determination of suitable class intervals, cumulative frequency plots of the untransformed and transformed values were constructed. Data with a true Gaussian distribution would produce a sigmoid cumulative frequency plot. If a cumulative percentage frequency is calculated and the cumulative percentage at each class interval is converted to its probit value (Table IX of Fisher \& Yates, 1963), then a straight line would result. Probit plots obtained for the untransformed and transformed data values are shown in Text-fig. $2 \mathrm{a}-\mathrm{d}$. 
Table 1. Summary table of available sperm concentration data from the larger published studies

\begin{tabular}{|c|c|c|c|c|c|}
\hline Reference & No. & $\underset{\left(\times 10^{6} / \mathrm{ml}\right)}{\operatorname{Mean}} \pm$ s.d. & $\begin{array}{c}\text { Median } \\
\left(\times 10^{6} / \mathrm{ml}\right)\end{array}$ & $\begin{array}{c}\text { Calculated } 95 \% \\
\text { range }^{*}\left(\times 10^{6} / \mathrm{ml}\right)\end{array}$ & $\begin{array}{l}\text { Quoted range } \\
\left(\times 10^{6} / \mathrm{ml}\right)\end{array}$ \\
\hline \multicolumn{6}{|l|}{ (A) Suspected infertile men } \\
\hline MacLeod \& Gold, 1951 & 1000 & $90 \pm 76$ & 74 & -59 to 239 & 1 to $500 \S$ \\
\hline Smith et al., 1977 & 189 & $48 \pm 49$ & n.a. & -48 to 144 & n.a. \\
\hline David et al., 1979 & 2889 & $71 \pm$ n.a. & 47 & n.a. & n.a. \\
\hline MacLeod \& Wang, 1979 & 9000 & $96 \pm$ n.a. & $76 \cdot 5$ & n.a. & n.a. \\
\hline Mortimer et al., 1982a & 1711 & $89 \pm 78$ & 65 & -67 to 244 & 0.01 to 635 \\
\hline \multicolumn{6}{|c|}{ (B) Infertility clinic patients within 6 months of spontaneous pregnancy } \\
\hline Bahamondes et al., 1979 & 185 & $68 \pm 50$ & 62 & -30 to 166 & 2 to 220 \\
\hline Homonnai et al., 1980 & 627 & $84 \pm 88$ & $45-50 \dagger$ & -88 to 256 & 0.5 to 629 \\
\hline \multicolumn{6}{|l|}{ (C) Men believed to be fertile } \\
\hline MacLeod \& Gold, 1951 & 1000 & $107 \pm 74$ & 90 & -38 to 252 & 1 to $500 \S$ \\
\hline Nelson \& Bunge, 1974 & 386 & $48 \pm 40$ & $40 \dagger$ & -30 to 126 & n.a. \\
\hline Rehan et al., 1975ף & 1300 & $79 \pm 57$ & 65 & -33 to 191 & 1.5 to 375 \\
\hline Smith et al., 19779 & 2543 & $70 \pm 66$ & $50 \ddagger$ & -59 to 199 & n.a. \\
\hline Zukerman et al., 1977$\rceil$ & 4122 & $63 \pm$ n.a. & $45-50 \dagger$ & n.a. & n.a. \\
\hline David et al., 1979 & 190 & $98 \pm$ n.a. & 86 & n.a. & n.a. \\
\hline
\end{tabular}

n.a. not available.

* Mean \pm 1.96 s.d.

$\dagger$ Interpolated by the present authors.

$\ddagger$ Interpolated by MacLeod \& Wang, 1979.

$\S$ Apparent range from Text-figures.

If Prevasectomy population.

Calculated mean values were compared with the medians obtained from the probit plots: for a true Gaussian distribution the mean and median should be identical. The median value should remain constant irrespective of any transformation applied to the data.

\section{Results}

The distribution of the untransformed data for the sample of 1711 men showed a high degree of skew towards low values (Text-fig. 1a). The effects of the data transformation on the frequency distributions are shown in Text-fig. $1 \mathrm{~b}-\mathrm{d}$.

The probit plots of the various transformations of the data are shown in Text-fig. 2. From these plots it is clear that for the present data $a \log _{e}$ transformation does not produce a normalized distribution but causes an opposite skew. Cube root transformation also yielded a curved probit plot indicative of a skewed distribution. The best straight line was obtained with a square root transformation.

Median and $95 \%$ ranges were obtained from the probit plots and are given in Table 2 for comparison with the calculated means and $95 \%$ ranges. All estimates of the median value were very close, and the calculated means for the square root and cube root transformations were nearest the median. While all estimates of the median should theoretically yield the same value, some variation is acceptable when they are obtained graphically. Reading the upper and lower limits of the $95 \%$ ranges from the probit plots necessitated extrapolation of the line in some cases.

The arithmetic mean and variance provided little information of value about the population; the mean was appreciably different from the median, and the lower limit of the $95 \%$ range was a negative number well below zero. 
Table 2. Mean and $95 \%$ range and median and $95 \%$ range from the appropriate probit plot for the untransformed and various transformations of sperm concentration $\left(10^{6} / \mathrm{ml}\right)$ from 1711 suspected infertile men (those with azoospermia excluded)

\begin{tabular}{|c|c|c|}
\hline Transformation & $\begin{array}{c}\text { Mean; } 95 \% \text { range } \\
\left(\times 10^{6} / \mathrm{ml}\right)\end{array}$ & $\begin{array}{c}\text { Median; } 95 \% \text { range* } \\
\left(\times 10^{6} / \mathrm{ml}\right)\end{array}$ \\
\hline None & $88.7 ;-66.9$ to 244.3 & $65.0 ;-10.0$ to 265 \\
\hline $\log _{e}$ & $51.9 ; \quad 12.3$ to 219.0 & $63.4 ; \quad 0.9$ to 228 \\
\hline Square root & $72 \cdot 8 ; \quad 0.3$ to $271 \cdot 3$ & $67.2 ; \quad 0.6$ to 253 \\
\hline Cube root & $66.7 ; \quad 0.8$ to 373.2 & $64.0 ; \quad 0.6$ to 244 \\
\hline
\end{tabular}

* Obtained from probit plots: median $=$ probit $5.00 ; 95 \%$ range $=$ probits 3.04 and 6.96 .

\section{Discussion}

Logarithmic transformation has been the most commonly used transformation for sperm concentrations (Rehan et al., 1975; Sobrero \& Rehan, 1975; Heuchel et al., 1981; Mortimer et al., 1982a). While it does provide better summary statistics than the simple arithmetic mean and variance, it is clearly not the ideal way in which to treat such data. The frequency distribution of the logtransformed data presented by Rehan et al. (1975) clearly indicates a skewed distribution, as also reported by Bahamondes et al. (1979), Heuchel et al. (1981) and Mortimer et al. (1982a, c).

Bahamondes et al. (1979) found that a cube root transformation produced an "almost straight line" cumulative frequency plot. Close inspection of their figure shows the plot to be very close to that obtained in the present study using such a transformation.

In agreement with the report of MacLeod \& Wang (1979), the present study has shown that the square root transformation provides better normalization of the distribution of sperm concentrations. It should, however, be stressed that the application of a transformation does not necessarily imply an equivalent biological relationship. Data transformations are purely mathematical manipulations which can be used to meet the stringent requirements of parametric statistical tests.

From the reports of Bahamondes et al. (1979), MacLeod \& Wang (1979) and the present findings, it would appear that the square-root transformation should hold equally well for populations of fertile and suspected infertile men. We would therefore urge other workers in this field to consider its application when making comparisons for sperm count data between or within populations of men.

We thank the staff of the Edinburgh Royal Infirmary Infertility Service, and Dr R. A. Coleman for assistance with the computing.

\section{References}

Bahamondes, L., Abdelmassin, R. \& Dachs, J.N. (1979) Survey of 185 sperm analyses of fertile men in an infertility service. Int. J. Androl. 2, 526-533.

David, G., Jouannet, P., Martin-Boyce, A., Spira, A. \& Schwartz, D. (1979) Sperm counts in fertile and infertile men. Fert. Steril. 31, 453-455.

Drife, J.O. (1982) Drugs and sperm. Br. med. J. 284, 844 845 .
Eliasson, R. (1978) Semen analysis. Environmental Health Perspectives 24, 81-85.

Fisher, R.A. \& Yates, F. (1963) Statistical Tables for Biological, Agricultural and Medical Research, 6th edn. Longmans, London.

Heuchel, V., Schwartz, D. \& Price, W. (1981) Withinsubject variability and the importance of abstinence period for sperm counts, semen volume and pre- 
freeze and post-thaw motility. Andrologia 13, 479485.

Homonnai, Z.T., Paz, G., Weiss, J.N. \& David, M.P. (1980) Quality of semen obtained from 627 fertile men. Int. J. Androl. 3, 217-228.

James, W.H. (1980) Secular trend in reported sperm counts. Andrologia 12, 381-388.

Jouannet, P., Czyglik, F., David, G., Mayaux, M.J., Spira, A., Moscato, M.L. \& Schwartz, D. (1981) Study of a group of 484 fertile men. Part I. Distribution of semen characteristics. Int. J. Androl. 4, 440-449.

MacLeod, J. \& Gold, R.Z. (1951) The male factor in fertility and infertility. II. Spermatozoon counts in 1000 men of known fertility and in 1000 cases of infertile marriage. $J$. Urol. 66, 436-449.

MacLeod, J. \& Wang, Y. (1979) Male fertility potential in terms of semen quality: a review of the past, a study of the present. Fert. Steril. 31, 103-116.

Mortimer, D., Templeton, A.A., Lenton, E.A. \& Coleman, R.A. (1982a) Semen analysis parameters and their interrelationships in suspected infertile men. Archs Androl. 8, 165-171.

Mortimer, D., Templeton, A.A., Lenton, E.A. \& Coleman, R.A. (1982b) The influence of abstinence and ejaculation-to-analysis delay on semen analysis parameters of suspected infertile men. Archs Androl. 8, 251-256.

Mortimer, D., Templeton, A.A., Lenton, E.A. \& Coleman, R.A. (1982c) Semen analysis parameters of a population of suspected infertile men. In Human Fertility
Factors, pp. 91-96. Eds A. Spira \& P. Jouannet. INSERM, Paris.

Nelson, C.M.K. \& Bunge, T.D. (1974) Semen analysis: evidence for changing parameters of male fertility potential. Fert. Steril. 25, 503-507.

Rehan, N.-E., Sobrero, A.J. \& Fertig, J.W. (1975) The semen of fertile men: statistical analysis of 1300 men. Fert. Steril. 26, 492-502.

Smith, K.D., Rodriquez-Rigau, L.J. \& Steinberger, E. (1977) Relation between indices of semen analysis and pregnancy rate in infertile couples. Fert. Steril. 28, 1314-1319.

Sobrero, A.J. \& Rehan, N.-E. (1975) Semen of fertile men. 2. Semen characteristics of 100 fertile men. Fert. Steril. 26, 1048-1056.

Templeton, A.A. \& Penney, G.C. (1982) The incidence, characteristics and prognosis of patients whose infertility is unexplained. Fert. Steril. 37, 175-182.

Toth, A. (1979) Reversible toxic effect of salicylazosulfapyridine on semen quality. Fert. Steril. 31, 538540.

Wyrobek, A.J. \& Bruce, W.R. (1978) The induction of sperm-shape abnormalities in mice and humans. In Chemical Mutagens, Vol. 5, Ch. 11, pp. 257-285. Eds A. Hollaender \& F. J. de Serres. Plenum, New York.

Zukerman, Z., Rodriguez-Rigau, L.J., Smith, K.D. \& Steinberger, E. (1977) Frequency distribution of sperm counts in fertile and infertile males. Fert. Steril. 28, 1310-1313.

Received 19 August 1982 